\title{
Mediastinal Primitive Neuroectodermal Tumour (PNET) - A Rare Case of Horner's Syndrome
}

\author{
ANIRBAN DAS, ${ }^{1}$ PARTHA PRATIM ROY, ${ }^{2}$ ANIRBAN SARKAR,${ }^{3}$ SAMADARSHI DATTA,${ }^{4}$ SUBIR DEY, ${ }^{5}$ NANDITA BASU ${ }^{6}$
}

\begin{abstract}
:
Primitive neuroectodermal tumour (PNET) is a rare mediastinal tumour which may infiltrate pulmonary parenchyma and chest wall. Histopathologically, it is a round cell tumour, and on immunohistochemistry, tumour cells express for CD-99 (MIC-2). Here we report a rare case of PNET presented as unresectable mediastinal tumour with chest wall infiltration, superior vena caval obstruction and Horner's syndrome in an adolescent female.
\end{abstract}

Keyword: Primitive neuroectodermal tumour (PNET), Mediastinal tumour, Horner's syndrome, Superior vena caval onbstruction, Round cell tumour, CD - 99.

\section{Introduction:}

Ewing's sarcoma family of tumours (ESFT) includes Ewing's sarcoma, Peripheral primitive neuroectodermal tumour (PNET) and Neuroepithelioma. ${ }^{1}$ PNET is a very rare, malignant, small round blue cell tumour (SRBCT) of neuroectodermal origin, which carries characteristic chromosomal translocations, $\mathrm{t}(11 ; 22)(\mathrm{q} 24 ; \mathrm{q} 12){ }^{2}$ It may affect any age group with peak incidence in adolescence, with female predilection. The most common site of this tumour is thoracic region, presenting as mediastinal mass lesion. In 1978, Askin first described PNET of chest wall which involves chest wall, ribs, and pulmonary parenchyma, hence it is called Askin tumour. ${ }^{2}$ Here we report a rare case of mediastinal PNET presenting with Horner's syndrome, superior vena caval obstruction and painful chest wall swelling.

\section{Case Report:}

An 18 years old, Muslim, female student presented with a painful, hard, localized swelling over the upper part of anterior chest wall on right side, and generalized swelling of face, neck, upper part of the chest and upper limbs for $1 \frac{1 / 2}{2}$ months. The chest wall swelling was of insidious in onset and progressively increasing in size, at presentation, its size was $4 \mathrm{~cm} \times 5 \mathrm{~cm}$. The swelling of the upper torso was of insidious in onset, gradually progressive, and associated with engorged, tortuous veins over the chest wall. Dry cough, shortness of breath without wheeze, conjunctival edema and congestion were present. She also complained of frontal headache, difficulty in swelling, hoarseness of voice, but no visual disturbance, nausea, vomiting, convulsion, altered level of consciousness, hemoptysis or fever. History of loss of weight $\&$ appetite was present. She was normotensive and non - diabetic. No addiction history was given. Her menstrual history was within normal limit.

On general survey, pallor was present, but no cyanosis, clubbing and palpable lymph node. Neck vein was engorged, non - pulsatile, and abdomino - jugular reflux was absent. Her pulse rate was 96 beats / minute, respiratory rate, 24 breaths / minute and blood pressure, 124/80 mmHg. There was swelling of face, neck, upper part of the chest and upper limbs. Examination of eye revealed partial ptosis, miosis, enophthalmos, ipsilateral facial anhydrosis and loss of ciliospinal reflex on right side, i.e., Horner's syndrome was present. On examination of respiratory system, a right sided, irregular, hard, tender swelling of $4 \mathrm{~cm} \times 5 \mathrm{~cm}$ in size over infraclavicular area with supraclavicular extension was revealed. It was fixed to underlying bony structure and overlying skin was also fixed, surface of the swelling was irregular. Direction of blood flow in engorged, tortuous veins over the chest wall was above downwards. Trachea was shifted towards left, and apex beat was in 5th intercostal space, $1 / 2$ inch medial to left midclavicular line. Vocal fremitus was diminished over infraclavicular, mammary, and inframammary areas on right side. Percussion note was dull

1. Assistant Professor, Department of Pulmonary Medicine, Medical College, Kolkata.

2. Professor\& H.O.D, Pulmonary Medicine, Medical College, Kolkata.

3. MD (TB \& Respiratory Medicine); Assistant Professor, Department of Pulmonary Medicine, Medical College, Kolkata.

4. RMO-cum-Clinical Tutor, Department of Pulmonary Medicine, Medical College, Kolkata.

5. Professor, Department of Pulmonary Medicine, Calcutta National Medical College, Kolkata.

6. Professor\& HOD, Pathology, Midnapore Medical College, Midnapore.

Correspondence: Anirban Das, Address: C/o Mr Pradip Das Peon Para, Bhatchala, P.O: Sripalli, Dist.: Burdwan, West Bengal, India, Pin: 713 103. E-mail:dranirbandas_chest@,rediffmail.com; Mob. : (0)9434672168 
from 2nd intercostal space downwards along right mid clavicular line, and also over apex, accompanied by percussion tenderness. Sternal percussion was dull. Diminished vesicular breath sound was audible over infraclavicular, mammary, and infrascapular areas on right side. No adventitious sound was audible and vocal resonance was diminished over corresponding areas where vocal fremitus was diminished. No ascites, hepatomegaly and lymphadenopathy were revealed on examination of abdomen. Examination of other systems revealed no abnormality.

Complete haemogram and blood biochemistry were within normal limit. Sputum for acid fast bacilli and malignant cell was negative. Chest X-ray P.A. view revealed a mass lesion occupying almost whole right hemiothorax with sparing the right costophrenic angle and erosion of postero - lateral part of right second rib. Medial border of the lesion was merged with mediastinum. (Fig.-1) Contrast enhanced CT scan of thorax showed right sided mass lesion originating

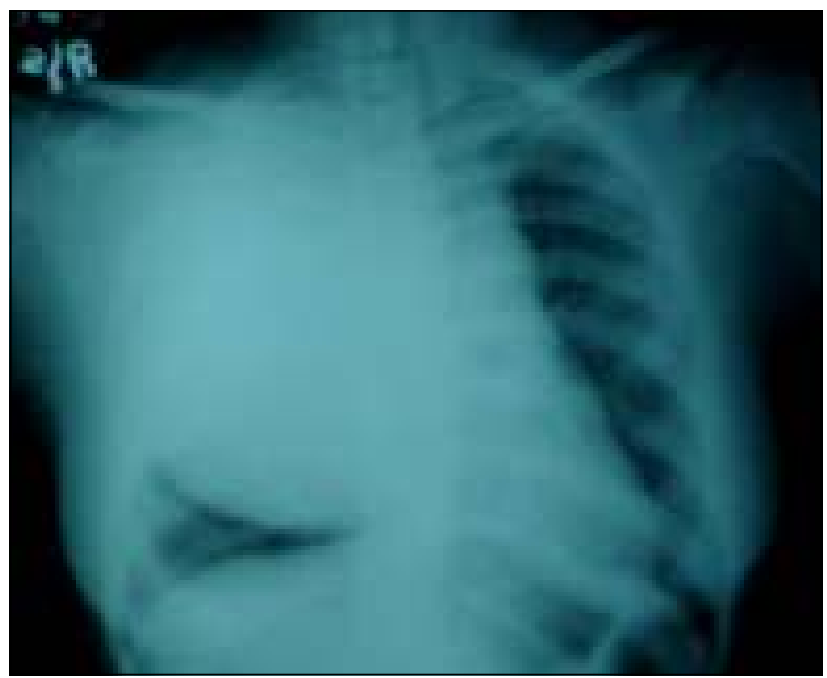

Fig.-1: Chest $X-$ ray P.A. view showing right lung mass with sparing the right costophrenic angle and erosion of postero - lateral part of right second rib

from mediastinum with erosion of ipsilateral second rib, but no pleural effusion. (Fig.-2) Fibreoptic bronchoscopy revealed no endobronchial mass lesion, although lumen of right bronchial tree is narrowed due to outside compression. CT guided FNAC revealed malignant neoplasm only, but definite pathological entity was not stated. Hence CT guided tru cut lung biopsy from right sided mass lesion was done and histopathology revealed sheets of small round cells with dark staining, round nuclei. (Fig.-3) Immunohistochemistry was done and tumour cells expressed CD-99 (MIC-2), (Fig. 4) but were immunonegative for cytokeratin, synaptophysin,

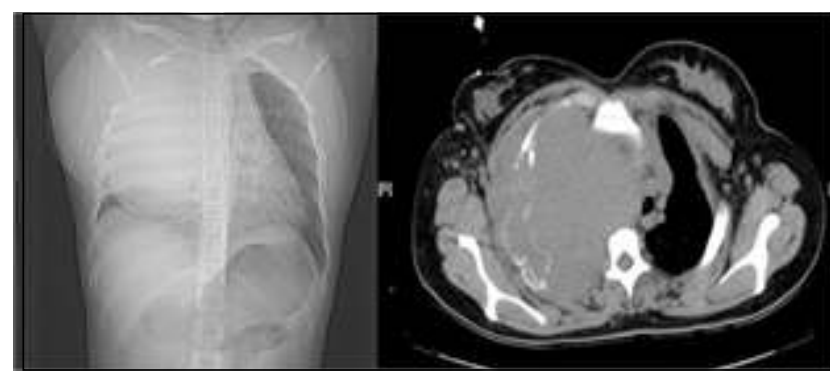

Fig.-2: CECT scan of thorax showing right sided mass lesion originating from mediastinum with erosion of ipsilateral second rib, but no pleural effusion

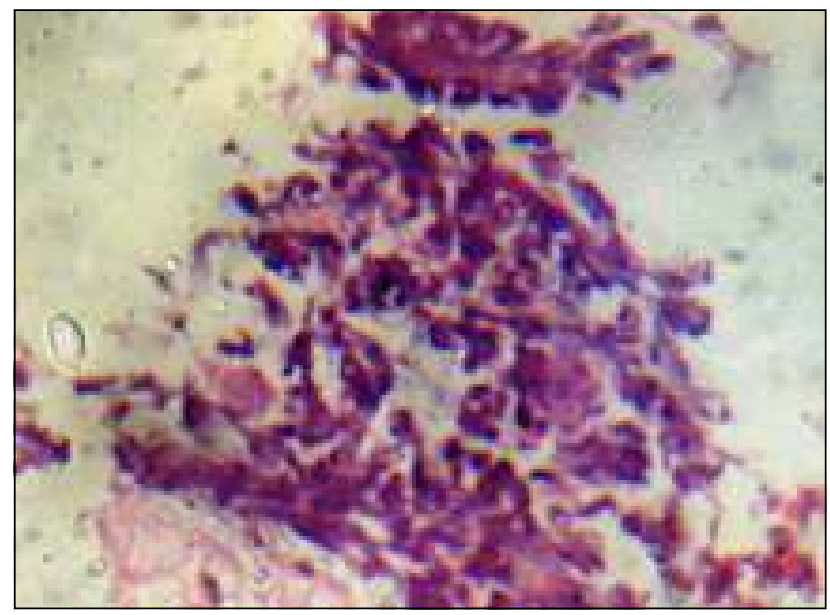

Fig.-3: HPE of CT guided tru cut lung biopsy showing sheets of small round cells with dark staining, round nuclei and little stroma (x100, H\&E stain)

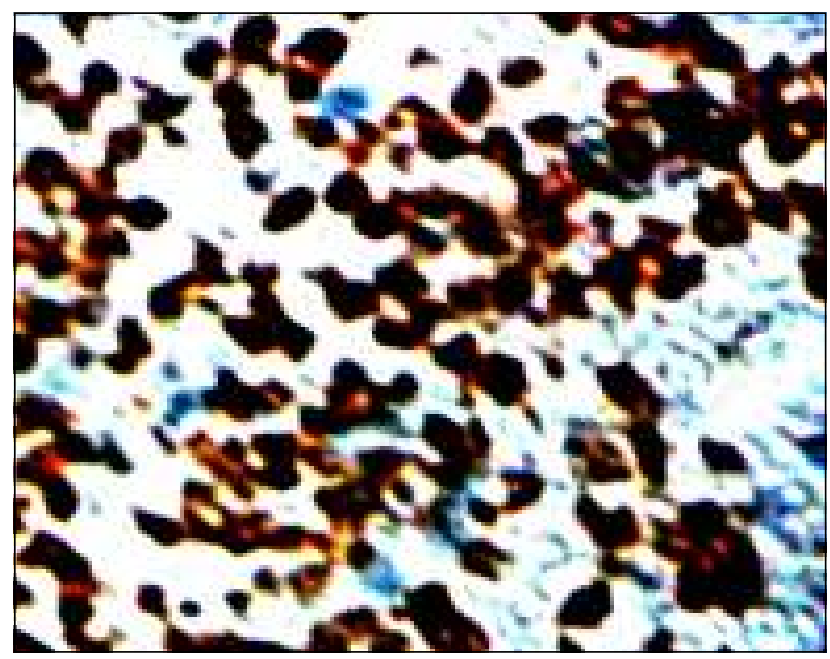

Fig.-4: Immunohistochemistry showing $C D-99$ positive tumour cells (x400)

chromogranin A, TdT and CD - 45. Serum LDH, $\alpha-H C G$ and $\alpha$-fetoprotein were within normal limit. USG of whole abdomen and contrast enhanced CT scan of brain revealed no abnormality. Hence our diagnosis was primitive 
neuroectodermal tumour (PNET) presenting as mediastinal mass lesion infiltrating right lung and anterior chest wall, complicated by superior vena caval obstruction and Horner's syndrome on right side. After exclusion of metastasis by extensive clinical examination and investigations, the patient was advised for cytotoxic chemotherapy, which was combined regimen of cyclophosphamide, vincristine and doxorubicin. But unfortunately, tumour was so aggressive that, the patient died before starting the regimen.

\section{Discussion:}

PNET is a rare (1.8\% of all mediastinal tumours), undifferentiated soft tissue sarcoma which is highly malignant tumour. ${ }^{3}$ It is believed that it arises from embryonal cells migrating from the neural crest. ${ }^{4}$ Ewing's sarcoma and PNET are different morphological expressions of a single neoplastic entity and have unique chromosomal translocation, $\mathrm{t}(11 ; 22)(\mathrm{q} 24 ; \mathrm{q} 12) .{ }^{1}$ PNET is most commonly seen in young females, especially in second decade of life. Kushner et al reported 54 patients with this disease in 1990 and incidence of affected sites was as follows : chest wall $(33.3 \%)$, pelvis $(22.2 \%)$, paraspinal region $(13.0 \%)$, retroperitoneum (11.1\%), limbs (9.3\%), abdomen (7.4\%), neck (1.9\%), and unknown site (1.9\%). Similar result was reported by Kennedy et al in $2000 .^{6}$

Thoracic involvement of PNET is characteristically painful, invasive thoracic tumours that may develop on and invade the chest wall, lung, or mediastinum. It is soft, fleshy, whitish or yellowish tumour with areas of hemorrhage and necrosis. Mediastinal mass lesion may result in superior vena caval obstruction, hoarseness of voice due to left recurrent laryngeal nerve palsy, Horner's syndrome due to involvement of cervical sympathetic trunk above the stellate ganglion, dysphagia due to esophageal compression and $\mathrm{C}_{8} \& \mathrm{~T}_{1}$ radiculopathy, when tumour extension occurs to pulmonary apex. Sites of metastases of PNET are lung, regional lymph nodes, bone, bone marrow. Histopathology of thoracopulmonary PNET is characterized by presence of monotonous sheets of small round cells with occasional rosettes formation like, Homer - Wright pseudorosette (central solid core of neurofibrillary material) and FlexnerWintersteiner pseudorosette (central lumen or vesicle). But histopathology alone can't confirm the diagnosis; hence immunohistochemistry is essential to establish the diagnosis. Tumour cells of thoracopulmonary PNET are CD99 positive but cytokeratin negative. CD99 positivity has $95 \%$ sensitivity for PNET. $^{7}$ In our case, the female patient presented in her second decade of life, with unresectable disease. Chest wall extension of her mediastinal lesion resulted in painful chest wall swelling, besides the superior vena caval obstruction, hoarseness of voice, dysphagia and Horner's syndrome which were due to mediastinal mass effect. She showed typical histopathological and immunohistochemical features of PNET.

Classically, thoracopulmonary PNET is a highly aggressive neoplasm with a mean survival of eight months. ${ }^{4}$ Prognosis is still poor despite multidisciplinary modalities of treatment which includes excision, localized radiotherapy and systemic chemotherapy (cyclophosphamide, vincristine, doxorubicin $)^{8}$, with a 2 year survival of $38 \%$ and a 6 year survival of $14 \%{ }^{3}$ But in case of localized disease, 5 - year survival rate of $60 \%$ has been described. ${ }^{9}$

\section{Conflict of Interest: None}

\section{References:}

1. Verma S, Prakash P, Yadav P, Srivastava D, Sharma SC. Primitive neuroectodermal tumour of the chest wall in an adult. JIACM 2008;9(3):237 - 9.

2. Askin FB, Rosai J, Sibley RK et al. Malignant Small Cell Tumour of the Thoraco-pulmonary region in childhood. A distinctive clinicopathological entity of uncertain histogenesis. Cancer 1979; 43:2438 - 51 .

3. Vaziri M, Pazooki A, Zahedi - Shoolami L. Mediastinal Masses: Review of 105 Cases. Acta Medica Iranica 2009; 47(4): $297-300$.

4. Reddy HR, Yick DG, Kamangar N. A case of primitive neuroectodermal tumor (PNET) of the chest wall in an adult. Chest 2009;136(4):325

5. Kushner BH, Hajadu SI, Gulati SC et al. Extracranial primitive neuroectodermal tumours. The memorial sloankettering cancer centre experience. Cancer 1991;67: $1825-9$.

6. Kennedy JG, Eustace S, Caufield R et al. Extraskeletal Ewing's sarcoma : a case report and review of literature. Spine 2000; 25:1996-9.

7. Folpe AL, Goldblum JR, Rubin BP, Shehata BM, Liu W, Dei Tos AP et al. Morphologic and Immunophenotypic Diversity in Ewing Family Tumors : A Study of 66 Genetically Confirmed Cases. Am J Surg Pathol 2005; 29(8): $1025-33$.

8. Miser JS, Krailo MD, Tarbell NJ, Link MP, Fryer CJ, Pritchard DJ et al. Treatment of metastatic Ewing's sarcoma or primitive neuroectodermal tumor of bone: evaluation of combination ifosfamide and etoposide - a Children's Cancer Group and Pediatric Oncology Group study. J Clin Oncol 2004; 22(14):2873 - 6 .

9. Nesbit ME Jr, Gehan EA, Burgert EO Jr et al. Multimodal therapy for the management of primary, non - metastatic Ewing's sarcoma of the bone: a long - term follow-up of the first Intergroup study. J Clin Oncol 1990;8(10):1664 - 74. 